Research Article

\title{
Development of the Modularity Measure for Assembly Process Structures
}

\author{
Vladimir Modrak iD and Zuzana Soltysova \\ Department of Industrial Engineering, Faculty of Manufacturing Technologies, Technical University of Kosice, \\ Presov 08001, Slovakia
}

Correspondence should be addressed to Vladimir Modrak; vladimir.modrak@tuke.sk

Received 22 April 2021; Revised 3 September 2021; Accepted 11 November 2021; Published 8 December 2021

Academic Editor: Mohammad Yaghoub Abdollahzadeh Jamalabadi

Copyright ( 2021 Vladimir Modrak and Zuzana Soltysova. This is an open access article distributed under the Creative Commons Attribution License, which permits unrestricted use, distribution, and reproduction in any medium, provided the original work is properly cited.

\begin{abstract}
This study is aimed at exploring the problem of quantification of process modularity degree. Modularity as a system design principle is apprehended here as the extent to which processes can be decomposed into modules to be executed in parallel and/or in series. For this purpose, a new method is proposed to measure relative modularity of different assembly process structures. This method is compared with other relative modularity measures, namely singular value modularity index, degree of process module, and process module independence, in order to verify its effectiveness. For this purpose, selected representative types of assembly process structures are used. This testing proved that the proposed relative modularity indicator for manufacturing and/or assembly process structures reflects the expected system property in adequate way.
\end{abstract}

\section{Introduction}

In wider sense, system modularity can be characterized as the degree to which a system is made up of relatively independent parts, while each part is typically carrying an isolated set of functionality [1]. System modularity concept, similar to system complexity, is an important element of general systems theory, since one can apply it to different kinds of systems such as technical, social, or biological systems, respectively [2,3]. Sako and Murray [4] identify three arenas of modularity, which are modularity-in-design (MID), modularity-in-use (MIU), and modularity-in-production (MIP). Manufacturing assembly processes that are of interest in this paper belongs to the third domain, where consequences of the MID have to be adapted to the factory floor. As MIP can be viewed from different aspects, here it is useful to introduce a working classification of system modularity as shown in Figure 1.

In line with this classification, process structure modularity is the subject of this paper. As known, final assembly lines especially in mass customization environment are faced with the greatest burden caused by product variability $[5,6]$.
Therefore, product components or modules under such conditions need to be assembled using work stations (process modules) with simple series of tasks instead of work stations integrating higher number of input components into one unit.

According to Ulrich [7], a product modular architecture is based on one-to-one mapping functional requirements to the design parameters. Such architecture follows the first axiom in the Axiomatic Design theory defined by Suh [8] specifying that each system function or functional requirement has to be satisfied by an independent design parameter. Subsequently, product design parameters are transformed into the production work order document determining the sequence of operations. An important feature of the system modularity is that complexity of technical systems can be effectively managed through their modular design [9-12]. Tate [13] categorized modularity from the Axiomatic Design theory perspective into three types: resource, operational, and interfacial. According to him, the resource modularity can be defined as "ease of manufacturing." This definition at least shows a certain connection between process modularity and complexity in 


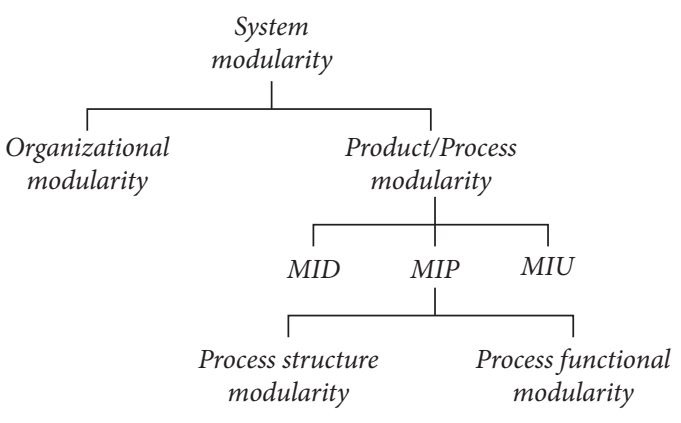

Figure 1: System modularity classification.

system design [14]. According to Mehrsai et al. [15], extension of modularity into processes and resources allows to generate alternative structures of organizations or supply chain networks by splitting their performances into modules and adjusting them as required. Mentioned works clearly show that product modularity and process modularity become increasingly important over the last decades, especially due to diffusion of mass customization. In this nexus, modularity measurement plays a vital role in product and process design.

\section{Literature Review and Related Works}

The vast majority of studies on modularity deal with product and organizational modularity (see, e.g., [16-19]). One of them has been offered by Ulrich [20] who provided a comprehensive overview of product modular design approaches in engineering. But there is considerable lack of studies on manufacturing process modularity. However, a few of them brought a partial insight into modularity in production. For instance, Starr [21] in his pioneering work on mass customization depicted that modular production is a very useful concept utilizing standardized and interchangeable parts and allowing to produce the so-called combinatorial outputs. Later, he emphasized how mass customization is related to modularity issues [22]. Calcagno [23] argued that there is a need to measure a degree at which a manufacturing system is modular. According to him, formalized concepts of process modularity should attract researchers' more and more attentions. In this context, one can identify research studies focused on the operational/ functional process modularity metrics [24-28]. Although, there is some relation between functional modularity and structural modularity [29], they differ in their nature. It is because that operational modularity measures aim to improve performance characteristics [30], and the goal of process structure modularity is the ease of changing from one product variant to another through layout design optimization [31].

Process modularity for mass customization was defined by Abdelkafi [32] as "the degree to which the production process on the shop floor can be broken down into independent subprocesses called process modules." This definition fully corresponds with a view on process structure modularity used in this paper. Langlois [33] identifies modularity as a very general set of principles for managing complexity. This statement is in line with the approach taken for development of the proposed indicator in this work. Other authors $[34,35]$ in their research discussed the possible relationship between product and process modularity. Nevertheless, one can claim that product modularity and process modularity differ in several respects. One of them is that expectations regarding process modularity are significantly different depending on preferred production strategy, while product modularity is the inherent part of product design. Another important issue regarding system modularity is its optimal level. As it is known, optimal modularity does not equate to maximal modularity [36-39]. Efatmaneshnik and Ryan [40] proved that optimal modularity can be achieved through balanced modularization by using a concept of structural symmetry in the distribution of the module sizes. The presented work was also inspired by methods focused on optimal assembly sequence generation and multistation assembly sequence planning [41-44]. The most relevant works to this research include works $[32,45,46]$, which will be analyzed in detail in a separate section of this paper.

\section{Methodological Framework}

First, have a look at the simplest structural model of manufacturing assembly process (MAP). As shown in Figure 2, its structure consists of the three obligatory element types which are input elements-at least two and more; one and more process operations; and minimum one output element.

As the topology of assembly process structures varies case by case and depends upon specific factors, it seems to be useful to create an initial classification framework of MAPs in order to model real processes more adequately (see Figure 3).

For this purpose, assembly process structures can be divided into the following classes:

(1) Single layer multiproduct (SLMP) assembly network: this class of MAP structures includes all single-step assembly networks with different numbers of input components, parallel single assembly operations, and output components. Selected alternative MAP structures, when the number of input components equals four and the number of output components equals six, are shown in Figure 3. Modularization followed here is based only on vertical fragmentation of the network modules into submodules.

(2) Multilayer single-product (MLSP) assembly network: all possible alternative MAP structures when the number of input components equals four and the number of output components equals one are shown in Figure 3. These networks are modelled as singlerooted tree graphs. The numbers of all possible process structures when a number of input elements are given can be exactly determined through the integer sequence A000669 [47] by using the formula: 


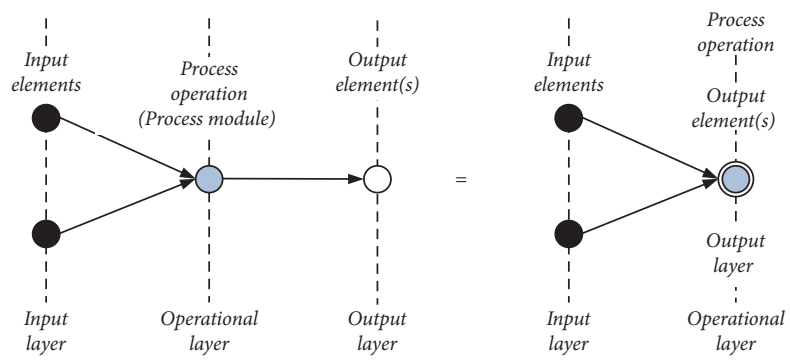

FIgURE 2: The generic model of manufacturing assembly process.
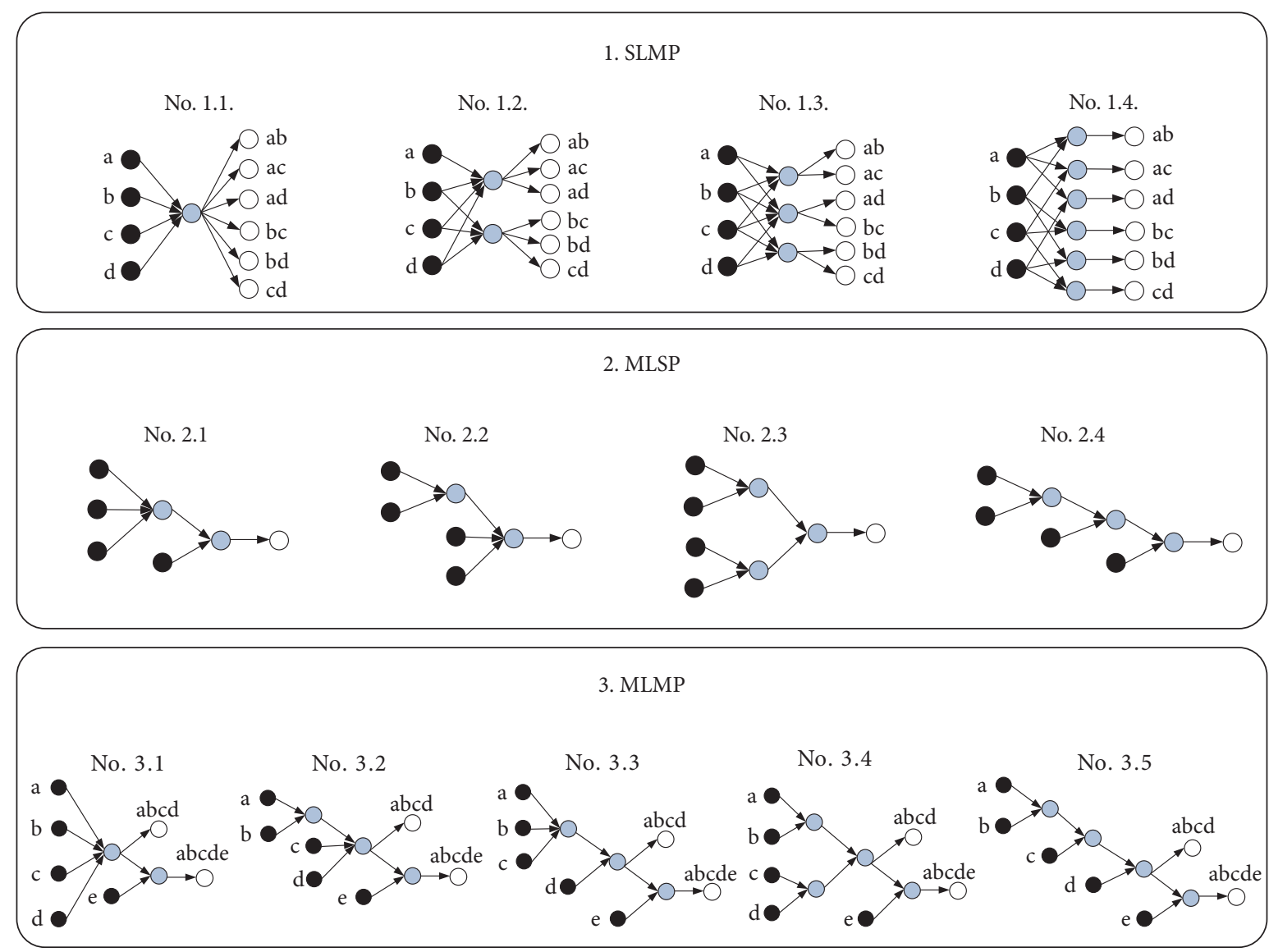

FIgURE 3: The assembly process networks classification. (a) SLMP. (b) MLSP. (c) MLMP.

$$
a(i)=A 000669(i)-1 \text {. }
$$

(3) Multilayer multiproduct (MLMP) assembly network: this class of MAP structures is important especially in terms of mass customization. Examples of such process alternative structures are shown in Figure 3.

Another purpose of this classification is to provide models of MAP structures with distinct assembly attributes that can influence computation of relative modularity in different ways.

\section{Description of the Modularity Measures}

4.1. Existing Modularity Measures. In the first part of this section, the following existing modularity indicators will be described: singular value modularity index (SMI), degree of process module $(\mathrm{M}(\mathrm{P}))$, and process module independence (PMI).

4.1.1. Singular Value Modularity Index. This index called singular value modularity index (SMI) quantifies the degree of modularity of a product on its internal structure, and it 
measures the average weighted decay rate of sorted singular values in the system. The following equation for its enumeration has been proposed [45]:

$$
\operatorname{SMI}\left(\Sigma_{\mathrm{DSM}}\right)=1-\frac{1}{N \cdot \sigma_{1}} \sum_{i=1}^{N-1} \sigma_{i}\left(\sigma_{i}-\sigma_{i+1}\right),
$$

where $N$ is the number of components of the system and $\sigma_{i}$ represents singular values, $i=1,2, \ldots, N-1$, ordered in decreasing magnitude.

This method is based on performing singular value decomposition on the binary design structure matrix (DSM), while singular values and corresponding orthogonal eigenvectors are expressed by the following equation:

$$
\mathrm{DSM}=U \cdot \Sigma_{\mathrm{DSM}} \cdot V^{T}
$$

where

$$
\Sigma_{\mathrm{DSM}}=\left[\begin{array}{ccc}
\sigma_{1} & 0 & 0 \\
0 & \ddots & 0 \\
0 & 0 & \sigma_{N}
\end{array}\right] .
$$

The SMI index is theoretically bounded between 0 and 1 . When SMI values are closer to 1 , it indicates a maximum degree of modularity, while SMI values closer to 0 indicate a minimum product modularity or integral product architecture.

Even though this indicator was originally dedicated to quantify degree of product modularity, its applicability for process modularity has been already proved in the work of [48]. To demonstrate its applicability on MAP process structures, let us use the selected process structure shown in Figure 4.

The procedure to calculate the singular values consists of the following six steps:

Step 1. Create adjacency DSM A for the process structure from Figure 4.

$$
A=\left[\begin{array}{lllll}
0 & 0 & 1 & 0 & 0 \\
0 & 0 & 1 & 0 & 0 \\
0 & 0 & 0 & 0 & 1 \\
0 & 0 & 0 & 0 & 1 \\
0 & 0 & 0 & 0 & 0
\end{array}\right]
$$

Step 2. Compute its transpose $A^{T}$.

$$
A^{T}=\left[\begin{array}{lllll}
0 & 0 & 0 & 0 & 0 \\
0 & 0 & 0 & 0 & 0 \\
1 & 1 & 0 & 0 & 0 \\
0 & 0 & 0 & 0 & 0 \\
0 & 0 & 1 & 1 & 0
\end{array}\right]
$$

Step 3. Compute the $A^{T} A$ matrix.

$$
A^{T} A=\left[\begin{array}{lllll}
0 & 0 & 1 & 0 & 0 \\
0 & 0 & 1 & 0 & 0 \\
0 & 0 & 0 & 0 & 1 \\
0 & 0 & 0 & 0 & 1 \\
0 & 0 & 0 & 0 & 0
\end{array}\right] *\left[\begin{array}{lllll}
0 & 0 & 0 & 0 & 0 \\
0 & 0 & 0 & 0 & 0 \\
1 & 1 & 0 & 0 & 0 \\
0 & 0 & 0 & 0 & 0 \\
0 & 0 & 1 & 1 & 0
\end{array}\right]=\left[\begin{array}{lllll}
1 & 1 & 0 & 0 & 0 \\
1 & 1 & 0 & 0 & 0 \\
0 & 0 & 1 & 1 & 0 \\
0 & 0 & 1 & 1 & 0 \\
0 & 0 & 0 & 0 & 0
\end{array}\right] .
$$

Step 4. Determine the eigenvalues of $A^{T} A$. In the first substep, set matrix $\left|A^{T} A-\lambda I\right|$ to zero, in order to obtain the homogeneous equation:

$$
\left|\begin{array}{ccccc}
1-\lambda & 1 & 0 & 0 & 0 \\
1 & 1-\lambda & 0 & 0 & 0 \\
0 & 0 & 1-\lambda & 1 & 0 \\
0 & 0 & 1 & 1-\lambda & 0 \\
0 & 0 & 0 & 0 & -\lambda
\end{array}\right|=0
$$

Then, solve the characteristic polynomial for the eigenvalues:

$$
\begin{aligned}
\left(2 \lambda^{2}-5 \lambda^{3}+4 \lambda^{4}-\lambda^{5}\right)+\left(-2 \lambda^{2}+\lambda^{3}\right) 0+0+0 & =0 \\
\left(-4 \lambda^{3}+4 \lambda^{4}-\lambda^{5}\right) & =0 \\
-\lambda^{3}(\lambda-2)(\lambda-2) & =0 .
\end{aligned}
$$

The obtained eigenvalues of matrix $A^{T} A$ are $2,2,0,0$, and 0 .

Step 5. Sort the eigenvalues in the descending order, in the absolute sense.

The eigenvalues of $A^{T} A$ in the descending order are given by $\lambda=2,2,0,0,0$.

Step 6. Identify of the singular values of matrix $A$.

Then, the singular values of $A-\sigma_{\mathrm{i}}$ are quantified as the square roots of the eigenvalues of $A^{T} A$ :

$$
\Sigma_{\mathrm{DSM}}=\left[\begin{array}{ccccc}
1,414 & 0 & 0 & 0 & 0 \\
0 & 1,414 & 0 & 0 & 0 \\
0 & 0 & 0 & 0 & 0 \\
0 & 0 & 0 & 0 & 0 \\
0 & 0 & 0 & 0 & 0
\end{array}\right] .
$$

Subsequently, it is possible to calculate modularity using SMI index by equation (2). Then, the degree of modularity of the process structure equals 0.7172 .

By applying this procedure, it is possible to quantify SMI values of the MAP process networks depicted in Figure 3. Enumerated values are available in Table 1.

4.1.2. Degree of Process Module. A concept of this indicator is based on assumption that a network is represented by directed graph $G(V, A)$, where $V$ is a set of nodes and $A$ is a set of interactions. A partition $P=\left\{V_{1}, V_{2}, \ldots, V_{M}\right\}$ is a set of 


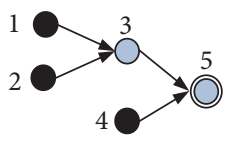

FIGURE 4: Selected example of assembly process structure.

TABLE 1: Process modularity values of MLSP type of MAPs.

\begin{tabular}{lcccc}
\hline & No. 2.1 & No. 2.2 & No. 2.3 & No. 2.4 \\
\hline SMI & 0.755 & 0.755 & 0.798 & 0.798 \\
M(P) & 0.417 & 0.417 & 0.245 & 0.245 \\
PMI & 0.17 & 0.17 & 0.29 & 0.29 \\
RNM & 0.157 & 0.157 & 0.21 & 0.21 \\
\hline
\end{tabular}

nonempty and nonoverlapping subsets of $V$, which covers $V$ (i.e., $V_{i} \cap V_{j}=\varnothing$, and $U_{i=1}^{M} V_{i}=V$ ). Then, the degree of process module extracted from the network is calculated by using formula [46]:

$$
M(P)=\sum_{i=1}^{M}\left(\frac{w_{v i v i}}{w}-\frac{w_{v i}^{\text {in }} * w_{v i}^{\text {out }}}{w^{2}}\right),
$$

where

$w_{V i V i}$ is the number of input and output edges of the individual module $V_{i}$

$w_{v i}^{\text {out }}$ is the number of output edges of the individual module $V_{i}$

$w_{v i}^{\text {in }}$ is the number of input edges of the individual module $V_{i}$

$w$ is the total number of interactions in the network

Then, the modularity of the network is expressed as $M(G)=\max M(P)$. Modularity values close to zero mean maximal modularity, and modularity values close to 1 indicate minimal modularity.

As a process operation, according to the generic model of MAP (see Figure 2), which is not decomposable module, then formula (11) can be simplified as follows:

$$
M(P)=\frac{w_{v i}}{w}-\frac{w_{v i}^{\text {in }} * w_{v i}^{\text {out }}}{w^{2}}
$$

where

$w_{V i}$ is the number of input edges into the individual module $V_{i}$

$w_{v i}^{\text {in }}$ is the number of input edges of the individual module $V_{i}$

$w_{v i}^{\text {out }}$ is the number of output edges of the individual module $V_{i}$

$w$ is the total number of interactions in the network

To show applicability of this indicator, let us have process structure in Figure 5.

This process structure is firstly divided into two operational modules. Then, the modularity for operational module \#1 and operational module \#2 is calculated using equation (12) as follows:

$$
\begin{aligned}
& M(P)_{1}=\frac{2}{5}-\frac{2 * 1}{5^{2}}=0.32, \\
& M(P)_{2}=\frac{2}{5}-\frac{2 * 1}{5^{2}}=0.32 .
\end{aligned}
$$

As modularity of the network equals the largest module, it is needed to choose the largest modularity value. Accordingly, the modularity of this process structure equals 0.32 .

4.1.3. Process Module Independence. Abdelkafi [32] adopted a cluster independence (CI) indicator for the measurement of product modularity developed by Newcomb et al. [49] in order to propose a modified indicator to measure module independence (MI). MI is defined as the ration of the sum of relations inside all modules to the sum of all relations:

$$
M I=\frac{\text { the sum of the relations inside all modules }}{\text { the sum of all relations }} .
$$

According to Abdelkafi [32] "cross-module independence (or degree of loose-couplings) is nothing else than $(1-M I)$."

Then, this assertion can be transformed into a process module independence (PMI) indicator expressed as

$$
\mathrm{PMI}=1-\mathrm{MI} \text {. }
$$

4.2. Proposed Modularity Measure. In this section, the novel relative modularity indicator will be introduced using the following assumptions.

Assumption 1. Typical MAPs are modelled as MLSP type structures as it was proposed by $\mathrm{Hu}$ et al. ([50], page 48).

Assumption 2. There is certain correlation between structural network complexity and network modularity $[9,10,13]$.

Assumption 3. Under the previous assumption, it is expected that if MAP modularity increases, then the average complexity of all the modules of MAP decreases, and vice versa.

Proposition 1. To measure average complexity of all the modules (AMC) of any MAP, the following formula is proposed:

$$
\mathrm{AMC}=\frac{\sum_{i=1}^{V} \operatorname{deg}(v)_{i} \log _{2} \operatorname{deg}(v)_{i}}{m},
$$

where

$\operatorname{deg}(v)_{i}$ is the degree of vertex of $(v)_{i}$ in graph $G$, while $G$ consists of a set of $V$ vertices $\{V\}=\left\{v_{1}, v_{2}, \ldots, v_{V}\right\}$

$m$ is the number of modules in the network 


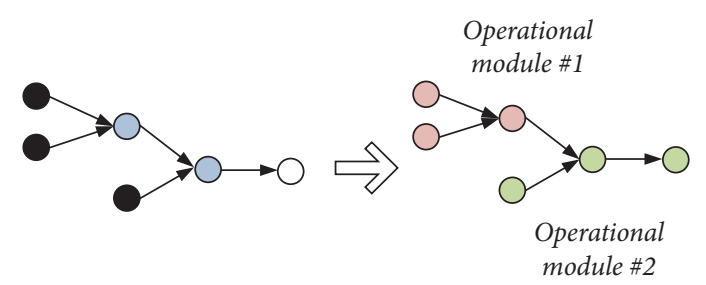

Figure 5: Example of process structure with two operational modules.

Proof. This proposition can be proved on SLMP networks from Figure 3, where one can see that MAP structure No. 1.1 is minimally modular or nonmodular, while No. 1.4 is maximally modular, and structure No. 1.3 is more modular than structure No. 1.2. When applying the AMC indicator for the selected networks, the following values are obtained and summarized in Table 2.

Now, it can be seen that the most modular network No. 1.4 has the lowest complexity, and the structure No. 1.1 which is minimally modular has the highest complexity. This relation also applies to the networks No. 1.2. and No. 1.3. This proves that AMC reflects complexity of the selected MAPs according to Assumption 3.

Proposition 2. Relative network modularity (RNM) of any $M A P$ can be measured through the inverse function of formula (16):

$$
\mathrm{RNM}=\frac{m}{\sum_{i=1}^{V} \operatorname{deg}(v)_{i} \log _{2} \operatorname{deg}(v)_{i}}
$$

Proof. The assertion of this proposition will be proved on MLSP networks from Figure 3. The proof is based on the deduction principle to show that if the order of degree of modularity of alternative MAPs is known, then modularity values of the MAPs using RNM should confirm the same order. By applying all the three existing modularity indicators, the order of degree of modularity of the MAPs can be achieved as highlighted in grey in Table 1.

Subsequently, the same order of degree of modularity of the MAPs is obtained using the RNM indicator. One can see that all the four indicators map modularity in the same way. This proves that RNM quantifies relative modularity of the selected MAPs in the same way as the three alternative indicators.

\section{Comparison of the Proposed Relative Modularity Indicator with the Existing Ones}

In this section, the abovementioned four indicators will be mutually benchmarked on SLMP and MLMP types of MAP models depicted in Figure 3. The obtained relative modularity values are shown in Table 3 .

The groups of MAP models in Table 3 are arranged in the ascending order in terms of the relative modularity. The order of SLMP type of MAPs has been already explained (see the proof of Proposition 1). The order of MLMP type of MAPs has been obtained by applying the three of the four indicators, namely, SMI, PMI, and RNM measures. All the
TABLE 2: Process complexity values of the selected assembly process networks.

\begin{tabular}{lcccc}
\hline & No. 1.1 & No. 1.2 & No. 1.3 & No. 1.4 \\
\hline AMC & 33,22 & 20,58 & 17,42 & 7,93 \\
\hline
\end{tabular}

three indicators brought the same degree of modularity tendency.

Nevertheless, according to the mutual comparison of values in Table 3, it can be seen that some values do not reflect the increasing order (see values in the boxes). It implies that SMI is not suitable for SLMP type of the MAPs, and $\mathrm{M}(\mathrm{P})$ is not suitable for MLMP type of the MAPs. Moreover, PMI is not applicable for SLMP type of the MAPs since it generates for all the four MAP structures zero values.

In addition, it is also evident that the RNM indicator can distinct small modularity differences between similar structures (see pair of structures No. 3.2 and No. 3.3), while the indicators SMI and PMI consider this pair of structures as identical in terms of modularity (see the values highlighted in grey).

In order to verify Proposition 2, all the indicators will be further comprehensively assessed on more complex examples of MAPs and compared according to the four criteria specified in Table 4.

As it can be seen from the Table 4, all the three existing indicators show at least one significant drawback, while RNM reflects all the criteria in positive way. This fact justifies to provisionally estimate this indicator as the most appropriate to evaluate structural relative modularity of manufacturing assembly processes.

In order to validate suitability of the proposed indicator and to test alternative indicators on more complex realistic cases, MAPs of MLSP type with six input components will be also used for this purpose (see Figure 6). The exact number of the alternative MAP structures is determined through formula (1) as follows:

$$
a(6)=A 000669(6)-1=32 \text {. }
$$

After generating of the all MAP structures for $i=6$ (see Figure 6), RNM, SMI, $M(P)$, and PMI values are calculated. The obtained values which are graphically presented in Figure 7 are arranged in ascending order according to the RNM values.

The following findings resulting from the computational data analysis employing evaluation criteria EC2 and EC3 can be summarized:

(i) SMI indicator does not satisfy EC2 and EC3 
TABLE 3: The obtained SMI, M(P), PMI, and RNM values.

\begin{tabular}{|c|c|c|c|c|c|}
\hline \multirow{2}{*}{\multicolumn{2}{|c|}{ Selected MAP structures }} & \multicolumn{4}{|c|}{ Obtained modularity values by using the indicators } \\
\hline & & SMI & $M(P)^{*}$ & PMI & RNM \\
\hline \multirow{4}{*}{ SLMP } & No. 1.1 & 0.811 & 0.76 & N/A & 0.03 \\
\hline & No. 1.2 & 0.857 & 0.468 & $\mathrm{~N} / \mathrm{A}$ & 0.046 \\
\hline & No. 1.3 & 0.837 & 0.344 & $\mathrm{~N} / \mathrm{A}$ & 0.057 \\
\hline & No. 1.4 & 0.895 & 0.161 & N/A & 0.126 \\
\hline \multirow{5}{*}{ MLMP } & No. 3.1 & 0.86 & 0.5 & 0.125 & 0.099 \\
\hline & No. 3.2 & 0.892 & 0.259 & 0.22 & 0.142 \\
\hline & No. 3.3 & 0.892 & 0.296 & 0.22 & 0.145 \\
\hline & No. 3.4 & 0.906 & 0.18 & 0.3 & 0.18 \\
\hline & No. 3.5 & 0.906 & 0.18 & 0.3 & 0.18 \\
\hline
\end{tabular}

${ }^{*} M(P)$ values range between 0 and 1 , while values close to 0 means maximal modularity and values close to 1 indicates minimal modularity.

TABLE 4: Assessment of the modularity indicators according to the four evaluation criteria.

\begin{tabular}{lcccc}
\hline $\begin{array}{l}\text { Process structure } \\
\text { modularity } \\
\text { indicators }\end{array}$ & $\begin{array}{c}\text { EC1: applicability for } \\
\text { all the MAP types }\end{array}$ & $\begin{array}{c}\text { EC2: ability to differ between } \\
\text { better and worse degrees of } \\
\text { modularity of MAPs }\end{array}$ & $\begin{array}{c}\text { Evaluation criteria (EC) } \\
\text { EC3: ability to recognize small } \\
\text { modularity changes in between two or } \\
\text { more MAPs with the proper tendency }\end{array}$ & $\begin{array}{c}\text { EC4: simplicity } \\
\text { of calculation }\end{array}$ \\
\hline SMI & $\checkmark$ & $\mathrm{X}$ & $\mathrm{X}$ & $\mathrm{X}$ \\
$M(P)$ & $\checkmark$ & $\mathrm{X}$ & $\mathrm{X}$ & $\checkmark$ \\
PMI & $\mathrm{X}$ & $\checkmark$ & $\checkmark$ & $\checkmark$ \\
RNM & $\checkmark$ & $\checkmark$ & $\checkmark$ \\
\hline
\end{tabular}

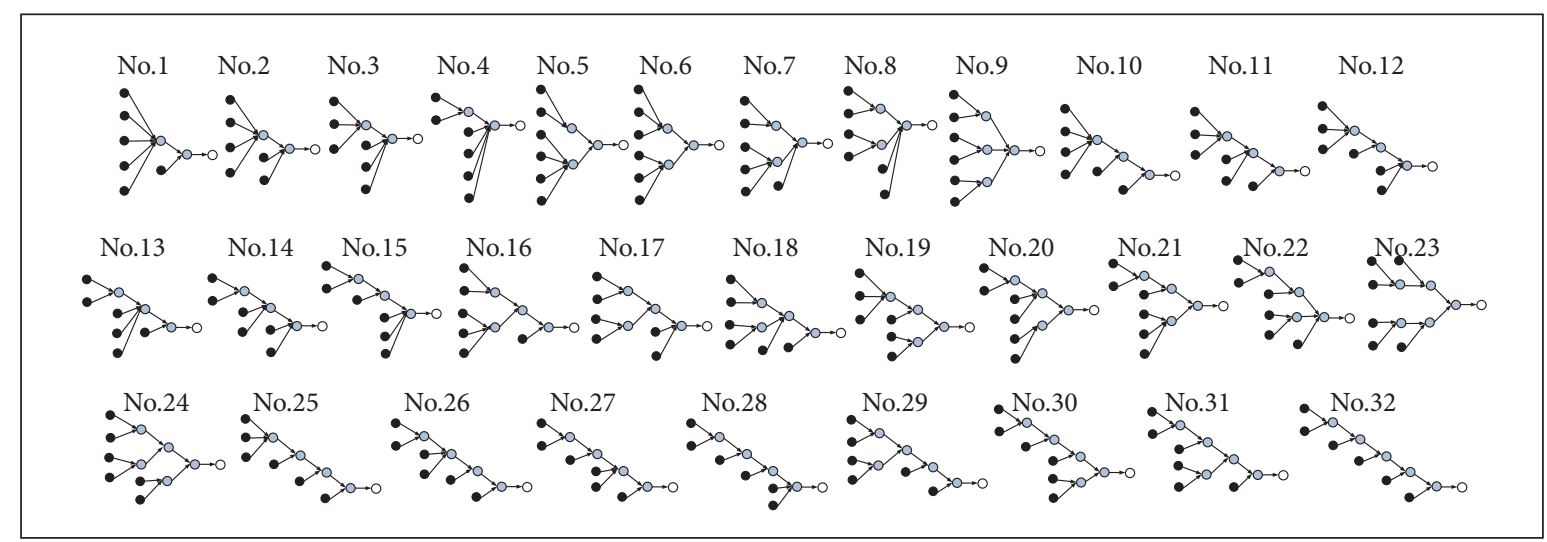

Figure 6: The all possible MLSP MAP structures with six input components.

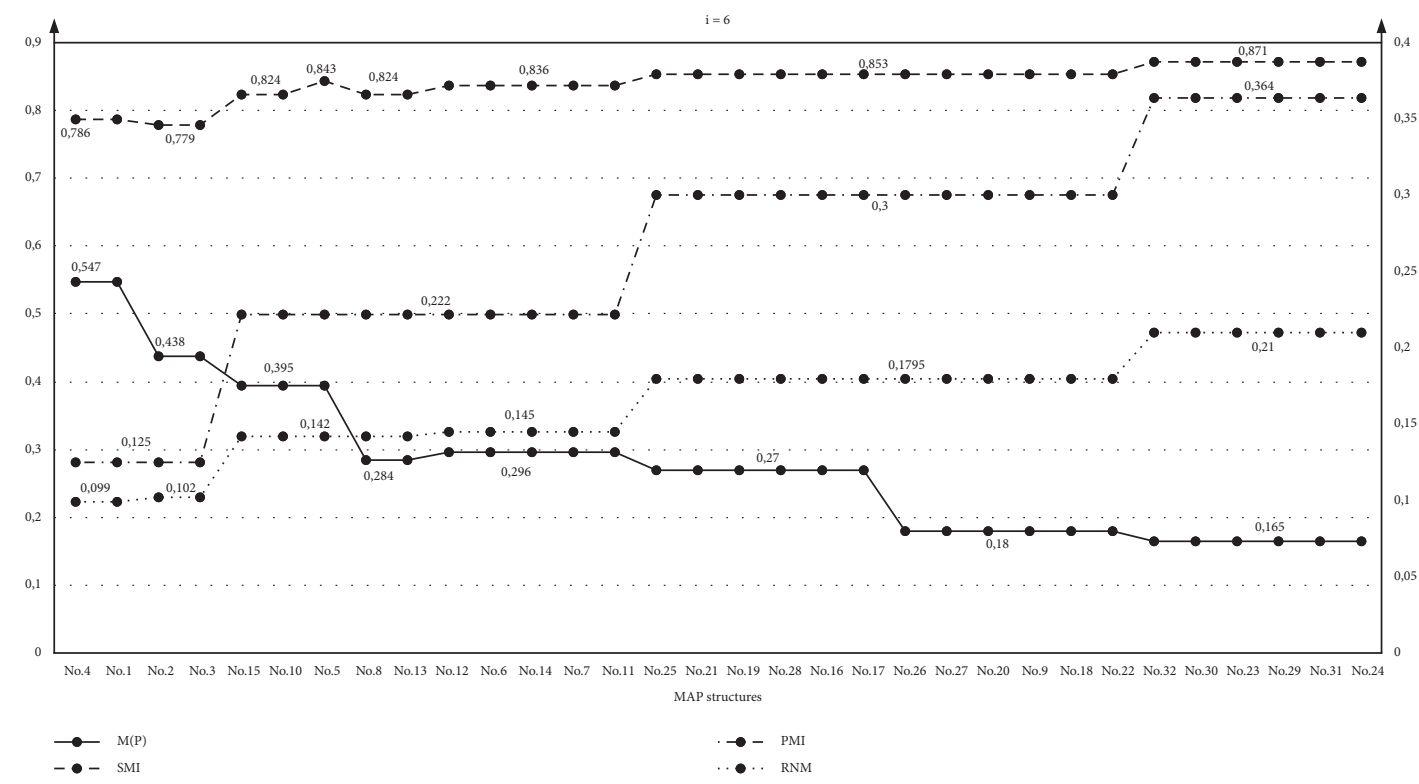

FIgURE 7: All possible MLSP process structures with six input components. 
(ii) $\mathrm{M}(\mathrm{P})$ indicator does not satisfy EC2 and EC3

(iii) PMI indicator satisfies EC2, but does not satisfy EC3

(iv) RNM indicator satisfies the both criteria EC2 and EC3

These four findings correspond in full scale with the results of the previous assessment of the four indicators shown in Table 4.

\section{Conclusions}

Building on the computational experiments, it can be stated that the RNM indicator reliably reflects the expected system attribute-relative structural modularity of the MAPs. Accordingly, this indicator can be considered as the most appropriate modularity measure from the compared ones because it is fully suitable for all the types of MAPs. Moreover, it does not require time-consuming calculation.

In addition, this paper offers the new assembly process networks classification which can help in further possible testing of modularity indicators. In this context, further research can be focused on testing more complex MAPs and verifying proposed indicator through real-case examples. The follow-up research could also be oriented towards analysing additional different assembly attributes that contribute to the relative modularity computation.

\section{Data Availability}

The data used to support the findings of this study are included within the article.

\section{Disclosure}

This is an extended version of a preliminary conference paper that was presented in the 14th International Conference on Axiomatic Design (ICAD 2021) 23rd-25th June 2021, Lisbon, Portugal [51].

\section{Conflicts of Interest}

The authors declare that there are no conflicts of interest regarding the publication of this paper.

\section{Acknowledgments}

This research was funded by the KEGA project granted by the Ministry of Education of the Slovak Republic (no. 025TUKE-4/2020).

\section{References}

[1] K. Sinha, E. S. Suh, and O. de Weck, "Integrative complexity: an alternative measure for system modularity," Journal of Mechanical Design, vol. 40, no. 5, 2018.

[2] M. A. Schilling, "Toward a general modular systems theory and its application to interfirm product modularity," Academy of Management Review, vol. 25, no. 2, pp. 312-334, 2000.

[3] C. Y. Baldwin and K. B. Clark, "Managing in an age of modularity," Managing in the modular age: Architectures, networks, and organizations, vol. 149, pp. 84-93, 2003.
[4] M. Sako and F. Murray, "Modules in design, production and use: implications for the global auto industry," in Proceedings of the IMVP Annual Sponsors Meeting, Cambridge, MA, USA, 1999.

[5] V. Modrak and Z. Soltysova, "Development of operational complexity measure for selection of optimal layout design alternative," International Journal of Production Research, vol. 56, no. 24, pp. 7280-7295, 2018.

[6] V. Modrak and Z. Soltysova, "Novel complexity indicator of manufacturing process chains and its relations to indirect complexity indicators," Complexity, vol. 2017, Article ID 9102824, 15 pages, 2017.

[7] K. Ulrich, "The role of product architecture in the manufacturing firm," Research Policy, vol. 24, no. 3, pp. 419-440, 1995.

[8] N. P. Suh, The Principles of Design, Oxford University Press, New York, NY, USA, 1990.

[9] S. K. Ethiraj and D. Levinthal, "Modularity and innovation in complex systems," Management Science, vol. 50, no. 2, pp. 159-173, 2004.

[10] D. B. Parker, "Modularity and complexity: an examination of the effects of product structure on the intricacy of production systems," Michigan State University, vol. 119, 2010.

[11] V. Modrak and D. Marton, "Configuration complexity assessment of convergent supply chain systems," International Journal of General Systems, vol. 43, no. 5, pp. 508-520, 2014.

[12] V. Modrak, S. Bednar, and Z. Soltysova, "Application of axiomatic design-based complexity measure in mass customization," Procedia CIRP, vol. 50, pp. 607-612, 2016.

[13] D. Tate, A roadmap for decomposition: activities, theories, and tools for system design, Ph.D. Thesis, Massachusetts Institute of Technology, Cambridge, MA, USA, 1999.

[14] V. Modrak and S. Bednar, "Using axiomatic design and entropy to measure complexity in mass customization," Procedia CIRP, vol. 34, pp. 87-92, 2015.

[15] A. Mehrsai, H. R. Karimi, and K.-D. Thoben, "Integration of supply networks for customization with modularity in cloud and make-to-upgrade strategy," Systems Science \& Control Engineering, vol. 1, no. 1, pp. 28-42, 2013.

[16] C. Y. Baldwin and K. B. Clark, "Design rules: the power of modularity," MIT press, vol. 1, 2000.

[17] R. Sanchez and J. T. Mahoney, "Modularity, flexibility, and knowledge management in product and organization design," Strategic Management Journal, vol. 17, no. S2, pp. 63-76, 1996.

[18] V. Modrak V, Mass Customized Manufacturing: Theoretical Concepts and Practical Approaches, CRC Press, Boca Raton, FL, USA, 2017.

[19] K. Frenken and S. Mendritzki, "Optimal modularity: a demonstration of the evolutionary advantage of modular architectures," Journal of Evolutionary Economics, vol. 22, no. 5, pp. 935-956, 2012.

[20] K. Ulrich, Fundamentals of Product Modularity Management of Design, pp. 219-231, Springer, Dordrecht, Netherlands, 1994.

[21] M. K. Starr, "Modular production-a new concept," Harvard Business Review, vol. 43, no. 6, pp. 131-142, 1965.

[22] M. K. Starr, "Modular production-a 45-year-old concept," International Journal of Operations \& Production Management, vol. 30, no. 1, pp. 7-19, 2010.

[23] M. Calcagno, "Dynamics of modularity: a critical approach," Euram Conference, vol. 9, no. 11, pp. 1-11, 2002.

[24] S. K. Vickery, X. Koufteros, C. Dröge, and R. Calantone, "Product modularity, process modularity, and new product introduction performance: does complexity matter?" 
Production and Operations Management, vol. 25, no. 4, pp. 751-770, 2016.

[25] R. Duray, P. T. Ward, G. W. Milligan, and W. L. Berry, "Approaches to mass customization: configurations and empirical validation," Journal of Operations Management, vol. 18, no. 6, pp. 605-625, 2000.

[26] B.-W. Lin, "Cooperating for supply chain effectiveness: manufacturing strategy for Chinese OEMs," International Journal of Manufacturing Technology and Management, vol. 5, no. 3, pp. 232-245, 2003.

[27] Q. Tu, M. A. Vonderembse, T. S. Ragu-Nathan, and B. RaguNathan, "Measuring modularity-based manufacturing practices and their impact on mass customization capability: a customer-driven perspective," Decision Sciences, vol. 35, no. 2, pp. 147-168, 2004.

[28] D. B. Parker, "Modularity and complexity: an examination of the effects of product structure on the intricacy of production systems," Unpublished doctoral dissertation, Michigan State University, East Lansing, MI, USA, 2010.

[29] Z. Toroczkai, "Functional vs. Structural Modularity: do they imply each other?" APS March Meeting Abstracts, vol. 9, no. 13, 2009.

[30] A. Muñoz Rios, Hexagonal Architecture in the Modernization of Corebanking Systems to Cloud, Transformation and Modernization, 2021, https://www.fintechna.com/articles/ hexagonal-architecture-in-the-modernization-ofcorebanking-systems-to-cloud/.

[31] J. M. Dasch and D. J. Gorsich, Survey of Modular Military Vehicles: Benefits and Burdens, Army Tank Automotive Research, Development and Engineering Center (TARDEC) Warren United States, Warren, MI, USA, 2016.

[32] N. Abdelkafi, "Variety induced complexity in mass customization: concepts and management," Erich Schmidt Verlag $\mathrm{GmbH}$ \& Co KG, vol. 7, 2008.

[33] R. N. Langlois, "Modularity in technology and organization," Journal of Economic Behavior \& Organization, vol. 49, no. 1, pp. 19-37, 2002.

[34] M. Jacobs, C. Droge, S. K. Vickery, and R. Calantone, "Product and process modularity's effects on manufacturing agility and firm growth performance," Journal of Product Innovation Management, vol. 28, no. 1, pp. 123-137, 2011.

[35] A. Kusiak, "Integrated product and process design: a modularity perspective," Journal of Engineering Design, vol. 13, no. 3, pp. 223-231, 2002.

[36] D. Standage, C. N. Areshenkoff, J. Y. Nashed et al., "Dynamic reconfiguration, fragmentation, and integration of wholebrain modular structure across depths of unconsciousness," Cerebral Cortex, vol. 30, no. 10, pp. 5229-5241, 2020.

[37] N. Kashtan and U. Alon, "Spontaneous evolution of modularity and network motifs," Proceedings of the National Academy of Sciences, vol. 102, no. 39, pp. 13773-13778, 2005.

[38] M. Kirschner and J. Gerhart, "Evolvability," Proceedings of the National Academy of Sciences, vol. 95, no. 15, pp. 8420-8427, 1998.

[39] G. P. Wagner, Robustness and Evolvability in Living Systems, Princeton University Press, Princeton, NJ, USA, 2005.

[40] M. Efatmaneshnik and M. j. Ryan, "On optimal modularity for system construction," Complexity, vol. 21, no. 5, pp. 176-189, 2016.

[41] Y. Yang, M. Yang, L. Shu, S. Li, and Z. Liu, "A novel parallel assembly sequence planning method for complex products based on PSOBC," Mathematical Problems in Engineering, vol. 2020, Article ID 7848329, 11 pages, 2020.
[42] M. R. Bahubalendruni, B. B. Biswal, M. Kumar, and R. Nayak, "Influence of assembly predicate consideration on optimal assembly sequence generation," Assembly Automation, vol. 35, no. 4, 2015.

[43] B. Wu, P. Lu, J. Lu, J. Xu, and X. Liu, “A hierarchical parallel multi-station assembly sequence planning method based on GA-DFLA," Proceedings of the Institution of Mechanical Engineers-Part C: Journal of Mechanical Engineering Science, vol. 203-210, Article ID 0954406220974065, 2020.

[44] M. R. Bahubalendruni and B. B. Biswal, "An intelligent approach towards optimal assembly sequence generation," Proceedings of the Institution of Mechanical Engineers-Part C: Journal of Mechanical Engineering Science, vol. 232, no. 4, pp. 531-541, 2018.

[45] K. Holtta K, E. S. Suh, and O. de Weck, "Tradeoff between modularity and performance for engineered systems and products," in Proceedings of the ICED 05: 15th International Conference on Engineering Design: Engineering Design and the Global Economy (Engineers Australia), pp. 449-450, Melbourne, Australia, January 2005.

[46] T. D. Tran and Y. K. Kwon, "The relationship between modularity and robustness in signalling networks," Journal of The Royal Society Interface, vol. 10, no. 88, Article ID 20130771, 2013.

[47] The On-line Encyclopedia of Integer Sequences (OEIS), 2021, https://oeis.org/A000669.

[48] V. Modrak and Z. Soltysova, "Process modularity of mass customized manufacturing systems: principles, measures and assessment," Procedia CIRP, vol. 67, pp. 36-40, 2018.

[49] P. J. Newcomb, B. Bras, and D. W. Rosen, "Implications of modularity on product design for the life cycle," in Proceedings of the International Design Engineering Technical Conferences and Computers and Information in Engineering Conference, Irvine, CA, USA, August 1996.

[50] S. J. Hu, X. Zhu, H. Wang, and Y. Koren, "Product variety and manufacturing complexity in assembly systems and supply chains," CIRP annals, vol. 57, no. 1, pp. 45-48, 2008.

[51] V. Modrak and Z. Soltysova, "Modularity measurement as a crucial design element," in Proceedings of the 14th International Conference on Axiomatic Design (ICAD 2021), Lisbon, Portugal, June 2021. 